\title{
Lessons from J.D. Eshelby
}

The measure of your education is what you remember 15 years afterward, says one wiseacre. Well, it's been a little more than 15 years, and I don't think that I learned anything at the time, but the lectures I had from Professor J.D. (Jock) Eshelby still leave a mark.

Undergraduate students in materials science at Sheffield University were barely aware of the towering stature of this man, in the intellectual sense anyway. If you don't know who he was or what contributions he has made, then you probably have some serious holes in your own materials education, but you can still read on. A few Britishisms must be explained, though. First, the term "Jock" is used in the United Kingdom not for an athlete, as in the United States, but is a nickname commonly accorded to Scotsmen living in England; the U.S. sense could never apply to Jock Eshelby. Second, the term "Faculty" in England is equivalent to a College in a U.S. university. Third, a professorship in the United Kingdom is a distinguished academic rank that has almost no equivalent in the United States; the closest would be a "leading professorship."

Way back then, Sheffield had a Faculty of Materials, with departments of Metallurgy, Ceramics, Glasses, Polymers, and the Theory of Materials. The Department of the Theory of Materials was arguably a little top heavy. It had two professors, Eshelby and B.A. Bilby (whose name you should also know), one other lecturer, and a computer programmer. In a good year it had one undergraduate student.

Eshelby taught courses in elasticity and solid state bonding to the undergraduates in all of the departments, and his lecturing style was not particularly student-friendly. He did not work from notes. He would walk into the lecture hall, apparently already half-way through his lecture, pick up the chalk, and start writing on the board. Whether he was trying to show us how to solve Schrödinger's Equation or develop the strain compatibility relations, the technique was always the same. He would clear a patch of the board and start deriving a theorem. Running out of space, he would clear another patch, not necessarily connected with the first, and fill that up. Eventually, small pieces of the theorem would be scattered more-or-less at random across the chalkboard, stochastically mixed with the detritus of the previous lecture, and with random parts missing - erased to make space for more. It did not help that his writing was atrocious, and his speech sounded as though he had filled his cheeks with marbles before starting. On one occasion, one of my classmates managed to get the professor's attention (a challenge) and asked him if he could possibly write a little more clearly. For a few lines, the writing was four times as large, but still as illegible as before. Several lectures ended with Eshelby's discovery that he had misderived the theorem in question-a significant risk if you try to do it without notes, even if you are a bona fide genius. When this happened, he would stand back and survey the board. After a few moments, he would announce something like, "Well, there's a sign error here. You can correct it and work through to the result for yourselves." As if.

As time went by, our horror at his teaching style gave way to an understanding that the man was, in fact, a genius. Eccentric, yes, but a genius. Apparently addicted to cheap cigars, he would smoke them down to the smallest butt, then draw a cherry pipe out of his pocket, and stuff the remains of the cigar into it, to be smoked until not a scrap of tobacco was left. He cared little for what people thought of him, I think, and did not pay much attention to the politics of academia and the scientific community. This resulted in an unconscionable delay in his being elevated to the rank of Fellow of the Royal Society, which does seem to have been a sore point. In one memorable lecture, he described all of the current theories on a particular topic, listing the names of their authors on an uncharacteristically cleared chalkboard. He then described what was wrong with each of their work, condemning the weak-mindedness of these "socalled scientists" in quite direct terms. Having disposed of their failed logic, he then wrote the magical letters "FRS" after each of the names. He was elected an FRS himself that year and did not repeat the performance as far as I can gather.

Eshelby's impact on materials science is far, far out of proportion to the numbers of his publications. In total, he published less than 20 papers over his entire career, but each of them is a classic. A fine demonstration of the futility of today's obsession with publication-counting as a means of career assessment. Eshelby's work is characterized by real physical insight, complemented by elegant mathematical analysis. (He was a professor of applied mathematics at Sheffield, in addition to being a professor of the theory of materials.) In contrast with his lectures, his written work is a model of clarity. Although he was a powerful mathemati- cian, he felt that we should only engage in "mathematical weightlifting" if we could not reason our way to the desired result through simple physical logic. Goodness knows what he would have made of today's computer simulation techniques. I think he would probably have thought of them as the last desperate resort after both physical reasoning and mathematical analysis has failed.

An insight into Eshelby's motivations was provided to us in an informal moment one day, sitting in the small but splendid museum of glassware belonging to the Faculty of Materials, in a traditional British tea break. The usually unapproachable Eshelby was unusually affable that day-perhaps he had just received word of his FRS election-but we fell into conversation and one undergraduate student asked him what had led to his being a "pure theoretician." He told us the story of a formative experience in his life. It seems that as a young teenager he had made a calculation of the thermal shock resistance of a piece of glass. This resulted from his mother's always using a thick cork pad beneath a coffeepot placed upon her glasstopped coffee table. She explained the reason to him and he set to work calculating the effect of the anticipated thermal shock. A short while later, he came to his mother and announced that he had completed his analysis, and that the table would withstand a sudden local rise to the boiling point of water. His mother, being a wise woman, advised him that the obvious experiment would not be forthcoming and that he was forbidden from performing it himself. Well, curiosity and the budding scientific mind got the better of his youthful judgement one day when he was alone in the house. He boiled a pan of water and placed it at the center of the prized coffee table. In his own words, "Well, cracks flew in every direction, and I subsequently received a discouragement from performing experiments that has lasted me the rest of my life."

True to the creed of the theoretician, however, he refused to allow that the analysis was flawed, and instead blamed the experiment. "Of course, I knew immediately what was wrong. The $\mathrm{d}^{* * * *} \mathrm{~d}$ thing hadn't been annealed properly. It was FULL of residual stress!"

By all accounts, this attack on the quality of the prized table did not endear him to his mother. Let all theorists beware of blaming the experiment lest they suffer similarly.

Alex KING 